\title{
Josefina Ludmer: el recorrido de una crítica en el Archivo Puig
}

\author{
Josefina Ludmer: the path of a critique in Puig's Archive
}

\section{Graciela Goldchluk \\ gracielagoldchluk@gmail.com \\ Programa de Crítica Genética y Archivos de Escritores. IdIHCS (UNLP-CONICET), Argentina}

Cita sugerida: Goldchluk, G. (2020). Josefina Ludmer: el recorrido de una crítica en el Archivo Puig. Orbis Tertius, 25(30), e177. https://doi.org/10.24215/18517811e177
Resumen: El hallazgo en el Archivo Puig de una versión no editada del artículo de Josefina Ludmer "Boquitas pintadas, siete recorridos" motiva un recorrido por las huellas que dejó en la escritura una amistad literaria que atravesó crítica y ficción.

Palabras clave: Josefina Ludmer, Boquitas pintadas, Archivo Puig, ARCAS.

Abstract: The find in the Puig Archive of an unedited version of Josefina Ludmer's article "Hearthbreak tango, seven tours" motivates a journey through the traces left in writing by a literaryfriendship that crossed criticism and fiction

Keywords: Josefina Ludmer, Heartbreak Tango, Puig's Archive, ARCAS.

En 1997, la Facultad de Humanidades fue sede del Primer Encuentro Internacional Manuel Puig, hasta el momento el único realizado. Una de las presentaciones de ese encuentro, recogida en el libro que coordinaron José Amícola y Graciela Speranza, fue la de Miguel Dalmaroni: “Todo argentino es héroe de Boquitas: Puig y la nueva crítica”, una lectura lúcida del trabajo de Josefina Ludmer que presentamos completo por primera vez en este número de Orbis Tertius. Allí se puede leer:

En 1971, la revista Actual de la Universidad de Los Andes de Mérida publicó uno de los primeros estudios críticos universitarios acerca de una novela de Manuel Puig. Me refiero al artículo firmado por Iris Josefina Ludmer, "Boquitas pintadas. Siete recorridos".

Se trata de un pormenorizado análisis narratológico -riguroso, controlado- (en el que no obstante podrían leerse rasgos de un proyecto de escritura crítica que apenas comenzado iba mostrando ya las armas de Ludmer: una relación articulada, digamos, entre la enunciación distante de la ciencia, y esa búsqueda de la fórmula del texto que deja despuntar siempre ciertos vértigos de la interpretación, ciertas repeticiones de la sintaxis destinadas al cautiverio o la captura de su lector o, según el caso, a su fastidio) (Dalmaroni, 1998, p. 104).

La intervención de Dalmaroni despliega las estrategias de la crítica, tanto en su acepción general de "la nueva crítica" como en la denominación de esa mujer que ejerció la crítica literaria con un tono cautivante y riguroso, según los atributos que el estudioso reconoce desde sus comienzos. ${ }^{1}$ Sobre la obra de Puig, Dalmaroni opina, en la frase que da fin a su artículo, que: 
la estética de Boquitas pintadas venía a proveer de objeto a una crítica que necesitaba darse a luz distinguiéndose decididamente de Contorno, es decir del realismo, pero sin hacerse irresponsable: sin dejar de rendir cuentas ante una moral política de vanguardia (ibid., p. 109).

Me interesa también la presentación de Dalmaroni porque a la vez que describe la operación retórica de Ludmer se muestra afectado por ella: el largo paréntesis con que describe su propio objeto de análisis, escandido de comas y expresiones tales como "digamos" o "según el caso", también es un estilo que se vuelve muy argentino. Acaso y al igual que los héroes de Boquitas, tan argentino que, como veremos, debió ser editado para su publicación en la revista venezolana Actual. Dalmaroni, invitado a hablar sobre Puig, se fascina con Ludmer como un alumno de los seminarios a los que no asistió, o porque Analía Gerbaudo tiene razón al preguntar: “¿quiénes fueron los alumnos de esos seminarios?, ¿solamente los presenciales?””

La felicidad de $\mathrm{ARCAS}^{3}$ nos permite ir y venir por el archivo de Manuel Puig y encontrar sorpresas, como una lista de la que participa Ludmer como candidata a personaje. En una esquina de sobre que se encuentra entre los apuntes pre-redaccionales de El beso de la mujer araña encontramos una lista donde hay varias mujeres de letras: además de Ludmer podemos reconocer a Martha Lynch, Luisa Futoransky, Luisa Valenzuela, María Cristina Forero (hoy más conocida como María Moreno, todavía Forero en la reuniones que compartió con Puig), entre las que aparecen como modelos posibles para resolver el problema planteado del otro lado del papel: definir She (la novia de Valentín) y la relación entre ambos. En vistas de dibujar ese personaje, Puig piensa en sus amigas: ${ }^{4}$

FIGURA 1

(EBMA, ID puig.NEbma.N.D.2.0010R)

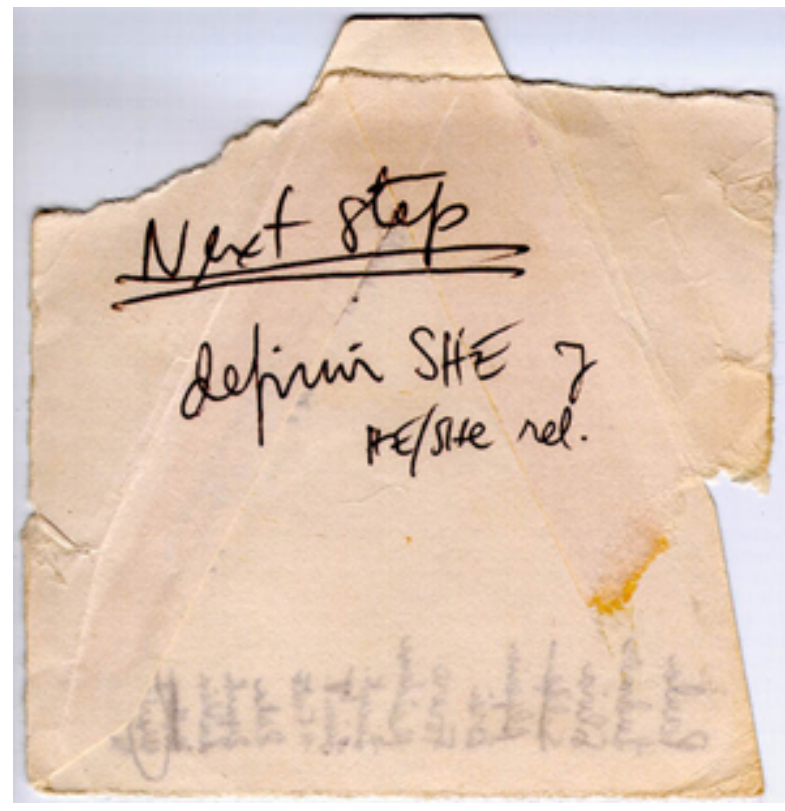


FIGURA 2

(EBMA, ID puig.NEbma.N.D.2.0010V)

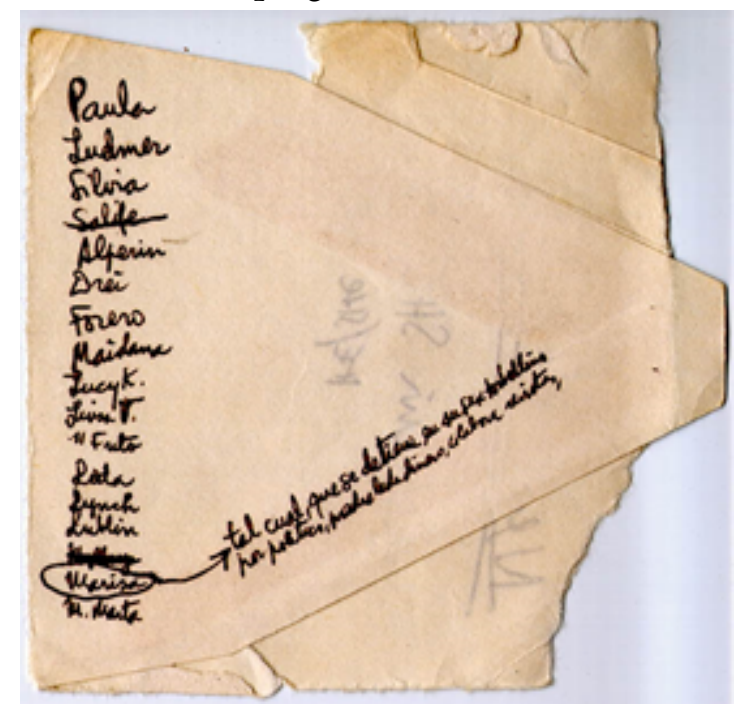

El desarrollo de las cualidades de la amiga que resulta elegida en 1975 para novia de Valentín se aplica sin dificultades a la "nueva crítica" de 1971. Dice de Marisa: "tal cual, que se detiene en su sex torbellino por política, padre le da dinero, colabora revistas". El sex torbellino, pero esto es una apreciación personal, sería una buena definición para la escritura de Josefina Ludmer: deseante, turbulenta, y sin embargo precisa, cerebral, potente.

Ludmer aparece otras veces en el archivo Puig en su carácter de crítica, no sólo de manera temprana y ligada a su intervención en Actual, sino también hacia los años ochenta, en una lista que reproducimos, escrita en el reverso del dactiloscrito de un artículo de Lucille Kerr de 1987. ${ }^{5}$ Casi como una novela en dos partes de ocho capítulos, acá vemos una lista de críticxs norteamericanxs y otra del resto del mundo:

U.S.A.
1. Pam [Pamela Bacarisse]
2. Kerr [Lucille Kerr]
3. Echav [Roberto Echavarren]
4. Giordano [Enrique]
5. Corbatta [Jorgelina]
6. Muñoz [Elías Miguel]
7. Piglia [Ricardo]
8. Campos [René]
9. Mc Adam [Alfred]

Alroad

1. Olver [Gilberto de León]

2. Ezquerro [Milagros]

3. Amícola [José]

4. Manfred [Engelbert]

5. Ludmer [Josefina]

6. Piglia [Ricardo]

7. Pauls [Alan] 


\section{Steimberg [Olga Steimberg de Kaplan]}

Ludmer es entonces una figura muy presente para Manuel Puig a lo largo de toda su trayectoria, una interlocutora cuya relación habría comenzado en los inicios de la crítica, según un testimonio que también se conserva en el archivo y está a la vista en ARCAS: en el reverso de un manuscrito de The Buenos Aires Affair:

FIGURA 3

(TBBA, ID puig.NTbaa.N.C.11.0125V)

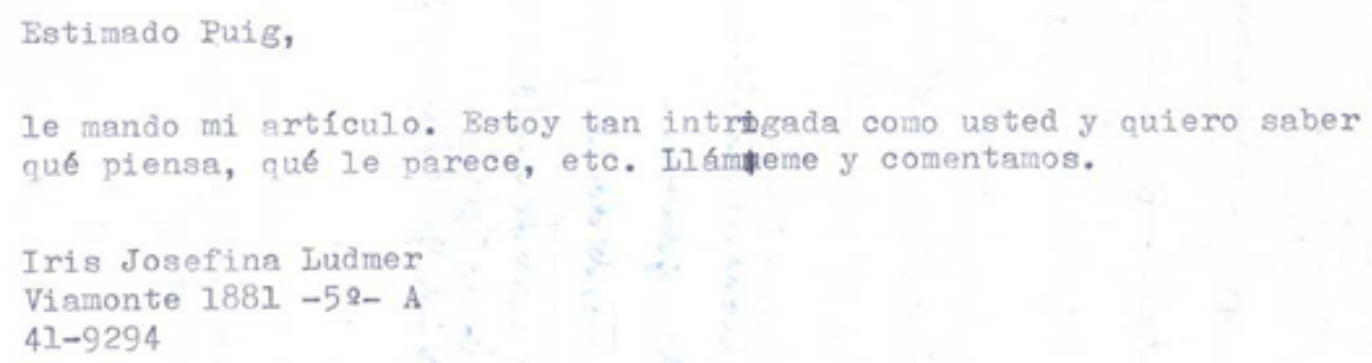

Ludmer se presenta "intrigada" y de eso quiere conversar. Es exactamente la motivación de Puig para escribir, responder sus propias preguntas; y es exactamente lo que estaba escribiendo Puig en ese momento, una intriga policial. Los reversos de los manuscritos tienen un lugar especial en un archivo: más allá del aprovechamiento del papel, indican un objeto que fue sostenido por el escritor, que fue mirado, utilizado y, al tratarse de apuntes prerredaccionales (es decir de planificación, de apuntes metaescriturarios) destinado a ser visto recurrentemente (Goldchluk, 2018). Escribir en el reverso equivale a mantener la nota en el escritorio, a mano. Escribir en el reverso de The Buenos Aires Affair es además, como demuestra Juan Pablo Canala en este mismo dosier, volver a mirar ese nombre y esa nota a lo largo de los años. Ahora bien, en la biblioteca de Manuel Puig se conservó un ejemplar de la revista Actual con el artículo publicado, pero además Puig guardó entre sus cosas aquel trabajo que Iris Josefina le había hecho llegar y que motivó una conversación cuyas marcas persisten en el archivo. Son veinticinco hojas tamaño oficio de un color celeste verdoso, con los bordes amarillentos, tipiadas a espacio y medio, con una versión pasada en limpio del artículo, presumiblemente la copia carbónica del trabajo entregado a la revista, que a partir de ahora se incorporan a ARCAS, en la sección "Documentos y para-textos" (puig_DDs_D_B_16_0001-0025).

En una primera etapa de archivación, me dediqué a organizar y describir los documentos producidos por Puig, al mismo tiempo que la familia se ocupaba de su digitalización. Poco a poco se iban apilando en un costado otros documentos tales como revistas, reportajes, artículos sobre la obra, cartas de amigos y editores, que fueron consultados para realizar algunas de las notas críticas de la correspondencia publicada en Querida familia (Puig, 2005 y 2006) a mi cargo, y del volumen Puigpor Puig, con selección de reportajes a cargo de Julia Romero (2006). El archivo que podríamos llamar "central” siguió su camino tanto en su versión física como digital, pero estos otros documentos permanecieron en el domicilio de Carlos Puig, hermano del escritor, con una clasificación provisoria hasta hoy. Los treinta años de la muerte de Manuel Puig suceden en un mundo bajo pandemia, que en Argentina nos ha obligado a permanecer más tiempo del habitual en nuestros domicilios. Resuelta la herencia de los papeles centrales se hicieron visibles estos otros, y gracias al diálogo sin interrupciones mantenido con Carlos Puig, ampliado ahora a todo el grupo de investigación en Crítica Genética y Archivos de Escritores (CriGAE), que permitió, además de la puesta en acceso abierto del archivo, la publicación del Álbum Puig(Rasic, Calvente, 2018), se abre otra etapa. Fue necesaria la colaboración de compañeras que ofrecieron su auto para traslados seguros y con permiso de atravesar una frontera provincial trayendo sanas y salvas doce cajas de cartón de $44 \times 32 \times 35 \mathrm{~cm}$ que contienen desde correspondencia enviada a la familia, pasando por el archivo de recepción, hasta algún original suelto. Esta es una etapa de ampliación 
del archivo que no implica, nunca implicó, la búsqueda de una totalidad. Ya demostré en mi tesis doctoral (Goldchluk, 2003) que, aunque Puig hubiera guardado una gran cantidad de papeles, no guardó todos, sino aquellos que quería para sí. Cuando hablamos de una nueva etapa es porque experimentamos en el cuerpo del archivo que "No hay un archivo, hay un proceso de archivación con etapas diferentes, pero nunca un archivo constituido. Hay etapas escandidas y articuladas en un proceso de archivación que no tiene un verdadero origen, un origen simple, en todo caso" (Derrida, 2013, p. 213). En esta etapa es cuando pudimos visualizar el ejemplar de Actual y compararlo con el dactiloscrito para comprobar, con sorpresa, que en la revista faltaban por lo menos cuatro hojas intermedias. En la primera parte "Cronografías", la publicación omite dos apartados completos: "Figuras" y "Oscilaciones". Mi primera impresión fue que podría deberse a problemas de espacio y diagramación, debido a que el apartado "Figuras" contiene un cuadro que podría ser de difícil reproducción para los medios con los que contara Actual, hipótesis que no pude comprobar pero que rápidamente cedió frente a otra comprobación de lectura: el artículo había sido editado, dado que no solo se eliminaba esta parte importante en la argumentación, sino que en varios lugares la autoridad tendía a contener ciertos "vértigos" (Dalmaroni), poner coto al "torbellino" (Puig) o moderar algunas referencias excesivamente argentinas.

Para quien haya leído el artículo publicado es difícil no advertir la desproporción entre el primer "recorrido" y los siguientes. Cada recorrido está señalado con un número romano: "I. Cronografías" es una lista de capítulos, unos pocos renglones con el título "Ejes" y de inmediato comienza "II. Cremar, quemar", que ocupa cuatro páginas de la prosa inconfundible de Ludmer. Si no se ha señalado esta extrañeza es porque al estar al comienzo parece una simple presentación con un título exagerado para lo que ofrece. Es en los apartados omitidos donde se desarrollan las "Figuras" que efectúan esa cronografía donde "no hay distorsión lógica ni temporal, no hay grandes juegos de tiempo (en años); los juegos se instauran a un nivel más sutil, a través de días, de meses: marcan encuentros, superposiciones y hiatos" (p. 3). Los ejes antes presentados son sólo una guía para poder entender estos dibujos, el apartado concluye:

Las figuras cronográficas son pues, al mismo tiempo, figuras de otro tipo: la primera dibuja, retrocediendo y avanzando, algo que podría llamarse "el nacimiento de la escritura"; la segunda abre y cierra hiatos, cierra y abre relaciones entre los personajes, alternativas, proyectos; cierra, sobre todo, la primera parte del relato y abre la segunda (p. 5).

Escritura, pero también relaciones entre personajes, relaciones de poder, proyectos, lo que Ludmer lee en la novela, en este y en los siguientes recorridos, está lejos de ser únicamente la novedad formal o una escritura autosuficiente. Pero hay algo más, y es la lectura minuciosa, hasta diríamos capciosa, que Ludmer desarrolla en el más breve apartado "Oscilaciones", donde le descubre a Puig un artificio que el escritor volverá a usar en otras novelas: pequeñas fallas temporales, errores cuidadosamente elaborados, que desencadenan sentidos e impiden el cierre de una interpretación única. ${ }^{6}$

Algo del estilo Ludmer se trasluce incluso en el tono de la breve misiva: "saber qué piensa, qué le parece, etc.", es un modo de armar series abiertas que volvemos a encontrar seis veces en el artículo dactilografiado y que el editor o editora de la revista cortan al eliminar el "etc.", de modo que las enumeraciones se cierran. También se elimina una nota al pie que habla de los monólogos interiores, acaso porque el tema había sido tratado en el apartado anterior, y desaparece la muy argentina referencia a "nuestra muñeca brava" (p. 22, n. 6). Más enigmática tal vez es la supresión de "dar la cara" como virtud y "no jugarse" como vicio (p. 20), que se revelan como idiolecto axiológico ajeno a los editores de la revista.

Recuperar hoy este documento implica, en primer lugar, que podamos acceder a los caminos efectivamente recorridos por la crítica en su lectura de Boquitas pintadas, precisamente aquel que habla de anacronismos deliberados; pero también permite que recuperemos parte de una conversación que propició una forma de amistad. Manuel Puig, que tuvo una vida itinerante en la que cargó pocos libros, que no atesoraba ni siquiera aquellos que le dedicaban, guardó amorosamente estas páginas (no falta ninguna) junto con sus papeles de trabajo, como si formaran parte de ellos. 


\section{REFERENCIAS}

Dalmaroni, M. (1998). Todo argentino es héroe de Boquitas. En J. Amícoa, y G. Speranza (comp.), Encuentro Internacional Manuel Puig (104-110). Rosario, Argentina: Beatriz Viterbo.

Derrida, J., et al, (2013 [1995]). Archivo y borrador. En G. Goldchluk y M. Pené (comps.), Palabras de archivo (205-233). Santa Fe, Argentina: Universidad Nacional del Litoral.

Ludmer, I. J. (2011 [1971]). Boquitas pintadas, siete recorridos. Actual Investigación, O (8), 3-22. Recuperado de http ://erevistas.saber.ula.ve/index.php/actualinvestigacion/article/view/1799/1753

Goldchluk, G. (2002). Distancia y contaminación. Estudio crítico-genético de la fase redaccional. En J. Amícola y J. Panesi (coords.), Manuel Puig. El beso de la mujer araña. Edición crítica. Madrid, España: ALLCA XX.

Goldchluk, G. (2003). Intertextualidad y génesis en los textos mexicanos de Manuel Puig: Novelas, guiones, comedias musicales (Tesis doctoral). Recuperado de http://www.memoria.fahce.unlp.edu.ar/tesis/te.157/te.157.pdf

Goldchluk, G. (2011). El diálogo interrumpido. Marcas de exilio en los manuscritos mexicanos de Manuel Puig. 1974\# 1978. Santa Fe, Argentina: Universidad Nacional del Litoral.

Goldchluk, G. (2018). El archivo Manuel Puig: un caso latinoamericano de creación en circulación. Manuscrítica, (35), 118-125. Recuperado de http://www.revistas.fflch.usp.br/manuscritica/article/view/3135

Puig, M. (2005). Querida familia: Tomo 1. Cartas europeas (1956-1962). G. Goldchluk (comp.). Buenos Aires, Argentina: Entropía.

Puig, M. (2006). Querida familia: Tomo 2. Cartas americanas: New York-Rio (1963-1983). G. Goldchluk (comp.). Buenos Aires, Argentina: Entropía.

Rasic, M. E. y P. Calvente (2018). Álbum Puig. La Plata, Argentina: Malisia.

Romero, J. (2006). Puig por Puig. Imágenes de un escritor. Madrid, España: Iberoamericana Vervuert.

\section{Notas}

1 Existen algunos artículos previos donde aparece la firma de Iris Josefina: Ernesto Sábato y el testimonio del fracaso, Boletín de Literaturas Hispánicas (5), 1963, 83-100; Estudio Q: una novela sobre la novela, Seiscientos monos (3, 8), agosto de 1966, 3, todos ellos corresponden al período de Ludmer en Rosario. A partir de su llegada a Buenos Aires y de su participación en la revista Los Libros abandona el Iris. La propia Ludmer, a propósito de una anécdota sobre David Viñas, comenta una curiosidad sobre su nombre propio: "Le debo la inspiración, la pasión por el trabajo crítico y mi nombre mismo porque yo me llamaba Iris Josefina y él, en una de esas tertulias que teníamos estudiantes y profesores en bares y parrillas de Rosario, me dijo: 'Piantá el Iris'”. Cuando escribe para Actual, Ludmer ya había publicado en Los Libros como Josefina, pero para hablar de Puig (y con él), desobedece a Viñas. Jornadas Viñas. Recuperado de https:// www.youtube.com/watch?v=fnsQQdsw2qE.

2 Durante la última dictadura militar, Josefina Ludmer organizó grupos de estudio en su departamento de la calle Viamonte. Con el regreso de la democracia, estas reuniones se convirtieron en multitudinarios seminarios dictados en la Facultad de Filosofía y Letras de la UBA, durante 1984 y 1985. En 2015, se organizó un homenaje en la UBA “A 30 años de los Seminarios Ludmer”, del que participaron Nora Domínguez, Analía Gerbaudo, Claudia Kozak, Gabriela Nouzeilles, Jorge Panesi, Alan Pauls, Adriana Rodríguez Pérsico, Matilde Sánchez y Miguel Vitagliano. Recuperado de https://www.youtube.com/watch?v=6zu7ZgimleM

3 Me refiero, por supuesto, al repositorio de fuentes útiles para la investigación donde se encuentra, en acceso abierto, el conjunto de manuscritos literarios de Manuel Puig. Recuperado de http://arcas.fahce.unlp.edu.ar/

4 Frente a una consulta relacionada con este dossier, Juan Pablo Canala comparte su ficha de investigación, que agradezco. Anota Canala para sí: “La lista de esas 'mujeres fuertes' constituyen un repertorio de figuras femeninas centrales dentro de la escritura de El beso de la mujer araña. Paula y Silvia, para la escritura de The Buenos Aires Affair y Pubis angelical. Pero además de tratarse de mujeres pensadas como modelos posibles, como cualidades a considerar en la construcción de la compañera de Valentín, arman en su conjunto heterogéneo, un mosaico de características que permiten reflexionar sobre las diversas formas de lo femenino en la novela, más allá de su encarnación física, más allá de la genitalidad de los personajes. Estas mujeres también pueden ser (también son) Molina y Valentín”. Los nombres identificados por Canala corresponden a: Paula [Wajsman] (la psicoanalista que Puig consultó para The Buenos Aires Affair); [Josefina] Ludmer; Silvia [Rudni] (cuya repentina enfermedad y muerte en el exilio resuena en Pubis angelical); Salife; Alperin; Drei; [María 
Cristina] Forero; Maidana; Lucy K[err]; Luisa V[alenzuela]; "” Futo[ransky]; Leda [Valladares]; [Marta] Lynch; [Lea] Lubin; [Sylvia] Molloy; Marisa; M. Marta.

5 La lista que sigue está tomada de una ficha descriptiva realizada por mí durante la primera etapa de organización del archivo. El trabajo de Kerr no se encuentra en lo que acá llamo “cuerpo central del archivo” y en cambio pertenece al grupo de documentos que todavía no fueron digitalizados y permanecen en algunas de las cajas en proceso de organización.

6 Lo que podría entenderse como errores en la primera edición que lee Ludmer se revela como decisión de escritura al corroborar que persisten las mismas fechas en sucesivas ediciones. Este mecanismo que introduce "fallas" en las fechas brindadas en el texto, por donde se cuela el afuera de la narración, es usado también en las fichas de prisioneros de El beso de la mujer araña(Goldchluk, 2002, pp. LXIX-LXXIII) y en el encadenamiento de historias de Pubis angelical(Goldchluk, 2011, pp. 168-172). 